\title{
The ability of streamflow models to capture the impact of climate variability on streamflow
}

\author{
$\underline{\text { A. Weeks }}^{\text {ab }}$, K. Barlow ${ }^{\text {ab }}$, F. Githui ${ }^{\text {ab }}$ and B. Christy ${ }^{\text {ab }}$ \\ ${ }^{a}$ Future Farming Systems Research, Department of Primary Industries, RMB 1145 Chiltern Valley Road, \\ Rutherglen, Victoria, Australia. ${ }^{b}$ eWater CRC, University of Canberra, ACT, Australia. \\ Email: anna.weeks@dpi.vic.gov.au
}

\begin{abstract}
This paper considers two streamflow models of the Ovens catchment in northeast Victoria and assesses the goodness-of-fit and variability of model predictions when calibrated over three different, historical, climate regimes. The aim was to understand whether the two models, calibrated using historical data, could be used to model future scenarios of climate-change where climate attributes such as rainfall, temperature and potential evaporation often lie outside the bounds of historical variability. To address this question, we looked to establish the influence of calibration data on model behaviour by assessing whether a model, calibrated over one climate regime, could adequately model streamflow over another climate regime.
\end{abstract}

The Ovens catchment in northeast Victoria, Australia was chosen as the study area. As the only largely unregulated catchment of the Murray River it provided a simplified connected system of streams to assess the validity of streamflow models. Two simple models of the Ovens catchment were established. The first model was constructed in Source (eWater, 2011) and consisted of a series of connected stream-nodes each modelled by Simhyd, a commonly used daily rainfall-runoff model. An identical stream network was constructed in CATPlus (DPI Victoria, 2011) with stream-nodes modelled using CATNode, a lumped surface-groundwater model designed to model temporal, surface and groundwater contributions of water yield and salt load to stream. Both models were calibrated using PEST, a non-linear, model-independent parameter estimation program (Watermark Numerical Computing, Australia 2010).

Based on annual rainfall over the Ovens catchment from 1975 to 2010, historical climate data were divided into three rainfall regimes; wet, medium and dry. For each climate regime the Simhyd and CATNode models were calibrated against streamflow data from that regime and then validated against streamflow data from the two other respective regimes. Three measures were used to assess the two models. First, the goodness-of-fit of each calibration and the subsequent validations were measured using a number of statistical measures including the Nash Sutcliffe coefficient of efficiency, percent difference in cumulative flow and the gradient of a regression line fitted to the measured versus modelled streamflow. Second, the uncertainty in streamflow attributed to the three different calibrations was calculated as the mean of the standard deviation in the monthly flow over the three calibrations as a proportion of the mean monthly flow. Third, the relative changes in streamflow between the different regimes were compared for the three calibrations.

Statistical analysis found that for each model over $90 \%$ of sub-catchments met the goodness-of-fit acceptability criteria. The models both validated well over the wet and average regimes, but validated poorly over the dry regime. Whilst the omission of factors such as extractions and dam releases may have contributed to this poor validation there was evidence that a model calibrated under wet conditions was biased towards those conditions. Consequently, if a future, drier scenario was used in these models, equivalent to moving from an average or wet regime to a dry regime, these models could potentially overpredict streamflow and under-estimate the impacts of climate change. On average the uncertainty in the monthly streamflow due to the different regimes of calibration was considerable, ranging between 8 to $35 \%$ of the mean monthly flow for the 22 sub-catchments. Although this uncertainty was large, in terms of assessing the impacts of climate change on streamflow it was perhaps more important to consider the uncertainty around the relative change in streamflow between different climate regimes. Results showed that the uncertainty associated with the percent decrease in streamflow ranged between 2.5 to $4.1 \%$ for CATNode and 4.1 to $6.6 \%$ for Simhyd. If under future scenarios of climate change the relative shift in streamflow was greater than this uncertainty we would now have greater confidence that this change was climate driven and not an artefact of the model calibration data.

Keywords: Climate change, rainfall, streamflow, Simhyd, CATNode, PEST, Source Catchments, CATPlus 
Weeks et al., The ability of streamflow models to capture the impact of climate variability on streamflow...

\section{INTRODUCTION}

A growing number of studies have started to look at how water resources may be impacted by future climatechange across Australia. These range from the simplistic approach used in the Guide to the proposed Basin Plan where current surface-water diversion limits were reduced by $3 \%$ across the Basin (Murray Darling Basin Authority, 2011) to more complex analyses that consider the impacts of multiple global climate models and downscaling techniques on streamflow generated by rainfall-runoff models (Chiew et al. 2009, Chiew et al. 2010). With the intention of applying some of the techniques of Chiew et al. (2010) it was first necessary to understand whether our existing streamflow models, calibrated using historical data, could be used to model future scenarios of climate-change where climate attributes such as rainfall, temperature and potential evaporation often lie outside the bounds of historical variability. To address this question, we looked at two streamflow models of the Ovens catchment in Victoria and assessed whether each model, calibrated over one historical climate regime, could adequately model streamflow over another historical climate regime. From this analysis we inferred the suitability of using the two selected models for assessing the impacts of future climate-change on streamflow.

\section{METHODS}

The Ovens catchment in northeast Victoria, Australia was chosen as the study area. Because of the largely unregulated nature of the catchment it provided a simplified system of connected streams to assess the validity of the streamflow models. A stream network was constructed in Source (v2.0.3, eWater CRC, Australia) and consisted of twenty-two connected stream-nodes each modelled by Simhyd, a daily rainfallrunoff model that has been used extensively across Australia (Chiew et al. 2010). An identical stream network was constructed in CATPlus (v8.4.3, DPI Victoria 2011) with stream-nodes modelled using

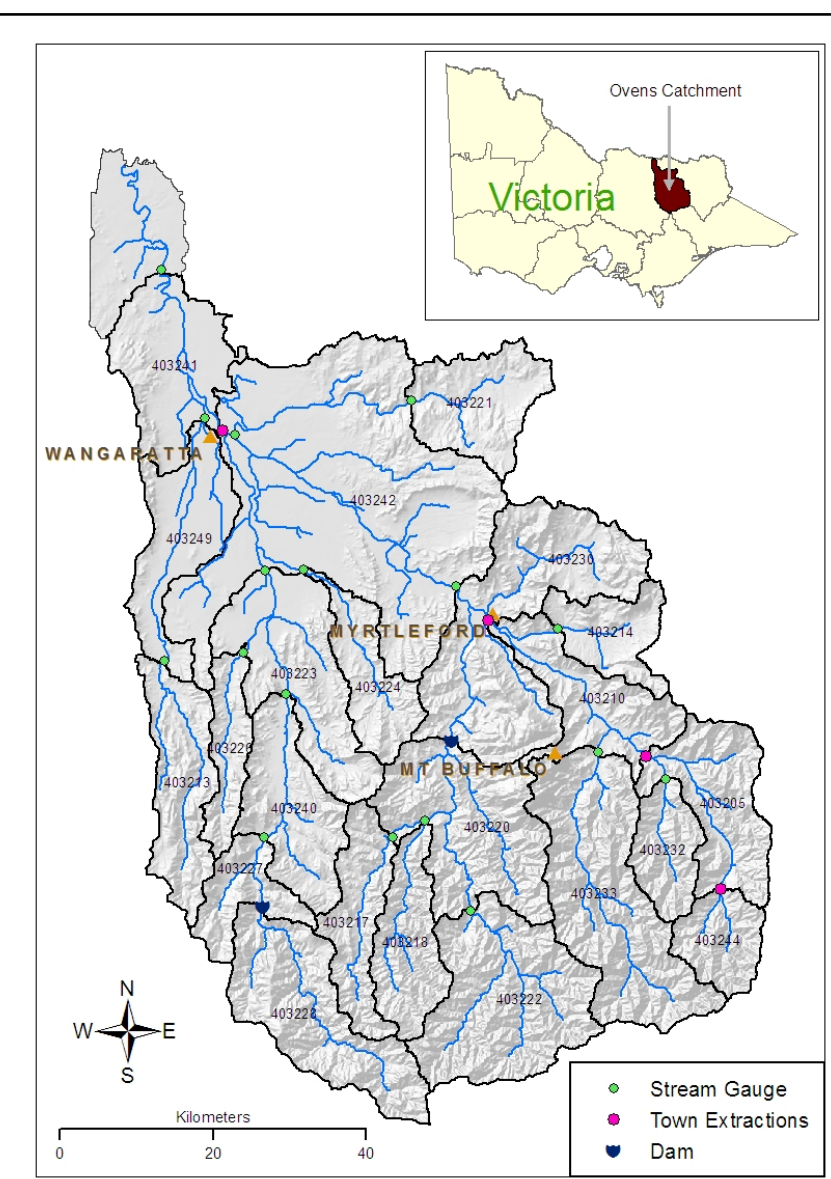

Figure 1. The stream network model of the Ovens catchment. Dams and extractions have been highlighted but not modelled in this analysis CATNode. All climate data was sourced from the SILO daily Data Drill $0.05^{\circ}$ grids (Jeffery et al. 2001). For this study where the focus was on the variability of the streamflow models under different calibrations, a simplified stream network model was used. A number of factors were not incorporated into the model which limited the achievable goodness-of-fit to measured streamflow at the gauged point, these included:

- Dam releases from the two main water storages within the catchment Lake William Hovell and Lake Buffalo (less than 3\% of mean annual streamflow at Wangaratta)

- Town extractions, groundwater and surface irrigation and farm dams (less than $0.35 \%$ of mean annual streamflow at Wangaratta (Barlow et al. 2011))

- Routing of water through the stream network (estimated lag time approximately 1 day from the top of the Ovens catchment to Wangaratta)

- Snow melt (Mt. Buffalo and alpine areas)

A recent study of the Ovens by Barlow et al. 2011 found that while the above factors improved the goodness-of-fit to measured streamflow the "challenge" of creating realistic models of dam releases and extractions that would hold under future climate conditions was "not necessarily warranted unless a significantly greater impact on streamflow was likely to occur". 
Weeks et al., The ability of streamflow models to capture the impact of climate variability on streamflow...

This paper compared two stream-node models of differing levels of complexity. The first model, Simhyd was a lumped, conceptual, rainfall-runoff model with daily inputs of rainfall and Morten's Wet potential evaporation (mwet). Simhyd estimated soil-evapotranspiration as a linear function of the soil moisture content, limited by potential evapotranspiration. The second model, CATNode was a lumped surfacegroundwater model, designed to predict surface and groundwater contributions of water-yield and salt-load to stream. The CATNode model was an extended version of the 2CSalt model originally developed by State agencies and associated partners of the Co-operative Research Centre for Catchment Hydrology and the Murray Darling Basin Commission (Stenson, et al. 2011). CATNode required inputs of monthly rainfall, recharge, runoff, subsurface flow and evapotranspiration which were sourced from CAT-1D, a daily biophysical water-balance model (Weeks et al., 2008). CATNode used broadly available data sets, and groundwater flow systems to parameterise the model. Whilst it was designed to be applied across large spaces with "little or no calibration" (Stenson, et al. 2011) parameters were still used to control the discharge rate of groundwater stores and the evaporation from shallow alluvial stores. A summary of the parameters calibrated in the Simhyd and CATNode models have been presented in Table 1.

Table 1. Initial values, upper and lower bounds of parameters calibrated in Simhyd and CATNode

\begin{tabular}{|c|c|c|c|c|}
\hline Model & Calibrated parameters & Initial value & $\begin{array}{l}\text { Lower } \\
\text { bound }\end{array}$ & Upper bound \\
\hline \multirow[t]{5}{*}{ Simhyd } & Soil moisture store capacity (mm) & 320 & 1 & 500 \\
\hline & Infiltration coefficient & 200 & 0 & 400 \\
\hline & Infiltration shape & 3 & 0 & 10 \\
\hline & Interflow coefficient & 0.1 & 0 & 1 \\
\hline & Rainfall interception store capacity (mm) & 1.5 & 0 & 5 \\
\hline \multirow[t]{3}{*}{ CATNode } & \begin{tabular}{|l}
$\alpha$ \\
$\quad$ The hillslope store discharge time (months) \\
\end{tabular} & 1 & 0 & 36 \\
\hline & $\begin{array}{ll}\lambda & \text { Evaporation from shallow alluvial stores ( } \% \text { of PAN evap) }\end{array}$ & 1 & 0 & 1 \\
\hline & $d_{\text {Evas }}$ Cutoff depth for evaporation from alluvial stores $(\mathrm{m})$ & 10 & 0 & Max store depth \\
\hline
\end{tabular}

The main difference between the two models was that the parameterisation of the Simhyd model determined the rate of evapotranspiration whereas the CATNode model used evapotranspiration from the biophysical water-balance model CAT-1D. Another difference was that Simhyd was calibrated on a daily basis while CATNode was calibrated on a monthly time-step. The Simhyd outputs were aggregated to a monthly timestep before calculating the goodness-of-fit to the measured data.

Based on annual rainfall over the Ovens catchment from 1975 to 2010, historical climate data were divided into three regimes; wet, medium and dry (Table 2). Each regime contained twelve years of daily climate data, including rainfall, potential evaporation (mwet), and the climate attributes required to run CAT-1D and generate the CATNode inputs. The 'Source-Simhyd' and 'CATPlus-CATNode' models of the Ovens catchment were each calibrated against streamflow data from the wet, medium and dry regimes respectively.

Table 2. Wet, average and dry regimes based on annual rainfall in the Ovens

\begin{tabular}{|l|l|l|l|l|l|}
\hline Regime & Years & $\begin{array}{l}\text { Mean } \\
\text { annual } \\
\text { rainfall } \\
(\mathbf{m m})\end{array}$ & $\begin{array}{l}\text { Mean } \\
\text { annual } \\
\text { mwet } \\
(\mathbf{m m})\end{array}$ & $\begin{array}{l}\text { Average } \\
\text { minimum } \\
\text { temperature } \\
\left({ }^{\circ} \mathbf{C}\right)\end{array}$ & $\begin{array}{l}\text { Average } \\
\text { maximum } \\
\text { temperature } \\
\left({ }^{\circ} \mathbf{C}\right)\end{array}$ \\
\hline Wet & $\begin{array}{l}1975, \quad 1978,1981,1983,1986,1988, \\
1989,1990,1992,1993,1996,2010\end{array}$ & 1323 & 1158 & 7.1 & 18.7 \\
\hline Average & $\begin{array}{l}1979,1980,1984,1985,1987,1991, \\
1995,1998,1999,2000,2003,2005\end{array}$ & 1067 & 1178 & 6.9 & 19.1 \\
\hline Dry & $\begin{array}{l}1976,1977,1982,1994,1997,2001, \\
2002,2004,2006,2007,2008,2009\end{array}$ & 760 & 1211 & 6.8 & 19.8 \\
\hline
\end{tabular}

The models were parameterised using PEST a non-linear, model-independent parameter estimation program (Watermark Numerical Computing, Australia 2010) that applies the Gauss-Marquardt-Levenberg algorithm to minimize the objective function, the squared sum of residuals between the observed and predicted time- 
Weeks et al., The ability of streamflow models to capture the impact of climate variability on streamflow...

series. Observed streamflow data were sourced from the Victorian-Water-Resource-Data-Warehouse to the end of 2010. The streamflow data were not in-filled; the models were calibrated against observed data only. All twenty-two sub-catchments were optimised simultaneously with different parameter values for every subcatchment. As such, the 'Source-Simhyd' model optimised 168 parameters and the 'CATPlus-CATNode' model, 124. PEST applied relative streamflow weighting between the individual sub-catchments and used truncated singular value decomposition to simplify the optimisation by systematically removing insensitive parameters. Three measures were used to assess each PEST optimisation of the two models;

1. The goodness-of-fit was measured using a number of statistical functions to assess the fit between measured and modelled streamflow data (Table 3). $Q_{0}$ was observed discharge, $\overline{Q_{o}}$ was mean observed discharge, $Q_{m}$ was modelled discharge at month $t,|x|$ referred to the absolute value of $x$.

Table 3. Statistical measures to calculate goodness-of-fit

\begin{tabular}{|c|c|c|c|}
\hline Description & Calculation & Range & Goodness of fit \\
\hline \multirow{3}{*}{$\begin{array}{l}\text { The Nash Sutcliffe } \\
\text { Coefficient of } \\
\text { Efficiency (CoE, Nash } \\
\text { and Sutcliffe 1970) }\end{array}$} & \multirow{3}{*}{$\operatorname{CoE}=1-\frac{\sum_{t=1}^{T}\left(Q_{o}^{t}-Q_{m}^{t}\right)^{2}}{\sum_{t=1}^{T}\left(Q_{o}^{t}-\overline{Q_{o}}\right)^{2}}$} & $0.8 \leq C o E \leq 1$ & Good \\
\hline & & $0.6 \leq \operatorname{CoE}<0.8$ & Acceptable \\
\hline & & $\operatorname{CoE}<0.6$ & Poor \\
\hline \multirow{3}{*}{$\begin{array}{l}\text { The Percent } \\
\text { Difference in } \\
\text { cumulative flow }\end{array}$} & \multirow{3}{*}{$\%_{-}$diff $=100\left(\frac{\sum_{t=1}^{T}\left(Q_{m}^{t}-Q_{o}^{t}\right)}{\sum_{t=1}^{T}\left(Q_{o}^{t}\right)}\right)$} & $\mid \% \_$diff $\mid \leq 10$ & Good \\
\hline & & $10<\mid \% \_$diff $\mid \leq 20$ & Acceptable \\
\hline & & $\mid \% \_$diff $\mid>20$ & Poor \\
\hline \multirow{3}{*}{$\begin{array}{l}\text { The gradient of a } \\
\text { regression line fitted } \\
\text { to the measured Vs. } \\
\text { modelled data }\end{array}$} & \multirow[t]{3}{*}{ Gradient } & $\mid$ Gradient $-1 \mid \leq 0.1$ & Good \\
\hline & & $0.1<\mid$ Gradient $-1 \mid \leq 0.2$ & Acceptable \\
\hline & & $\mid$ Gradient-1 $\mid>0.2$ & Poor \\
\hline
\end{tabular}

2. The uncertainty in streamflow attributed to the three calibrations was calculated as the mean of the standard deviation in the monthly flow over the three calibrations as a proportion of the mean monthly flow.

3. The uncertainty due to the different calibrations in the relative change in streamflow between the climate regimes was assessed by calculating the percentage decrease in streamflow between different regimes. For example, the percent decrease in streamflow between the wet regime and the average regime for a given calibration $\operatorname{Cal}(i)$ was calculated as

$\%$ decrease in streamflow ${ }_{\text {WET regime } \rightarrow \text { AVG regime }}^{\text {Cal }(i)}=\frac{\bar{Q}_{m,(\text { WET regime })}-\bar{Q}_{m,(\text { AVG regime })} \text { Cal }(i)}{\bar{Q}_{m,(\text { WET regime })}^{C a l ~}(i)}$

Results show the mean and standard deviation of equation (1) over the three calibrations.

\section{RESULTS AND DISCUSSION}

\subsection{Goodness of fit}

For each climate regime the Simhyd and CATNode models were calibrated against streamflow data from that regime and then validated against streamflow data from the two other respective regimes. The goodness-offit was used to inform on the ability of the two models to match streamflow over each calibration period then predict streamflow over the two validation regimes. Because of the simplified stream-network-model used it was expected that there would be some deviation between the measured and modelled data particularly over the dry regime where a higher proportion of the total streamflow would be diverted for town extractions, farm dams and irrigation.

Results presented in Figure 2 show the goodness-of-fit of the calibrations, highlighted by the grey columns and validations, highlighted by the white columns. Statistical analysis for both the CATNode and Simhyd models showed that the calibration of over $90 \%$ of all sub-catchments met the goodness-of-fit acceptability criteria under all climate regimes $(\mathrm{CoE}>0.6$, $\mid$ gradient $-1 \mid<0.2$ and the percent difference in cumulative flow less than 20\%). The goodness-of-fit over the validation regimes depended on calibration regime. Generally, 
Weeks et al., The ability of streamflow models to capture the impact of climate variability on streamflow...

both models over-predicted streamflow for the dry-regime when calibrated against streamflow data from the wet or average regimes. In contrast, calibration over the dry period did not lead to 'poor' validation over the wetter regimes. Given that acceptable calibration was achievable over the dry period it was likely that some bias was introduced into the model by only calibrating against periods average and wet rainfall years, however this would need to be confirmed by running the same analysis with the inclusion of extractions and dam releases. This would have particular implications for analysing the impacts of future climate sequences on streamflow as most future scenarios show a trend of decreased rainfall across the Ovens catchment, an analysis synonymous with calibrating over a wet or average regime then analysing or validating over a drier regime.
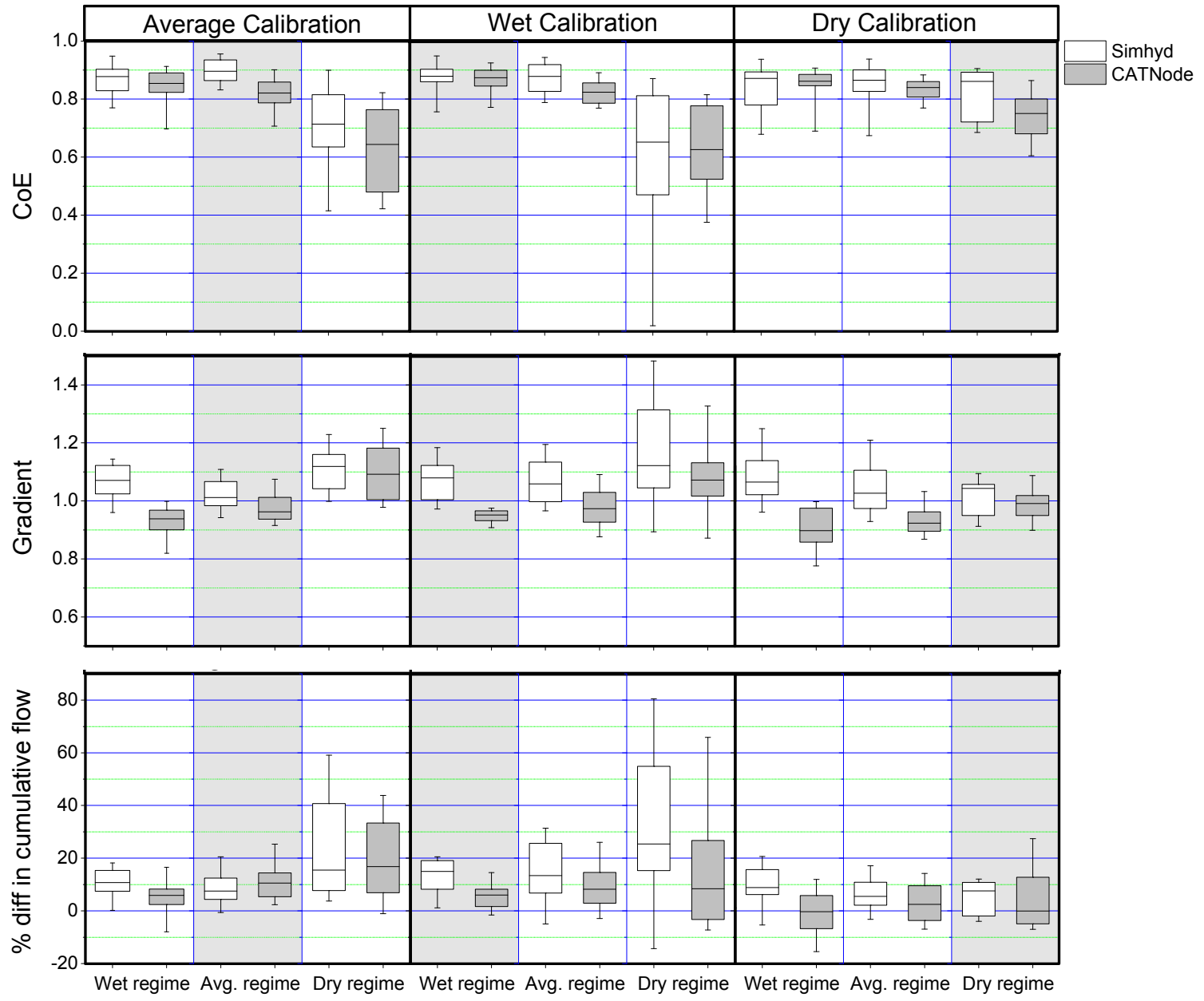

Figure 2. Summary statistics including the $\mathrm{CoE}$, gradient and percent difference in cumulative flow averaged over the 22 optimised sub-catchments of the Ovens. Box plots show the $10^{\text {th }}$ percentile, $25^{\text {th }}$ percentile, median, $75^{\text {th }}$ percentile and $90^{\text {th }}$ percentile. The grey columns represent the calibrations and the white columns represent the validations.

\subsection{Uncertainty of model predictions attribute to different calibrations}

The uncertainty in streamflow attributed to the three different calibrations was calculated as the mean of the standard deviation in the monthly flow over the three calibrations as a proportion of the mean monthly flow (Figure 3). This uncertainty ranged between 8 to $35 \%$ over the 22 sub-catchments. CATNode averaged $11.4 \%$ and Simhyd $13.7 \%$ however this difference was not statistically significant $(\mathrm{p}=0.32)$. Larger deviations were observed in the sub-catchments with lower mean-monthly flows which were generally the upland sub-catchments of the Ovens. The considerable variation in the monthly volumes of streamflow between the three calibrations was additional evidence that the calibration data could introduce a bias into the modelled streamflow. Notably, the actual difference in the average mean monthly flow between the Simhyd and CATNode models was small highlighting that on average the two models predicted similar mean monthly flows when presented with the different sets of calibration data (Figure 3). 


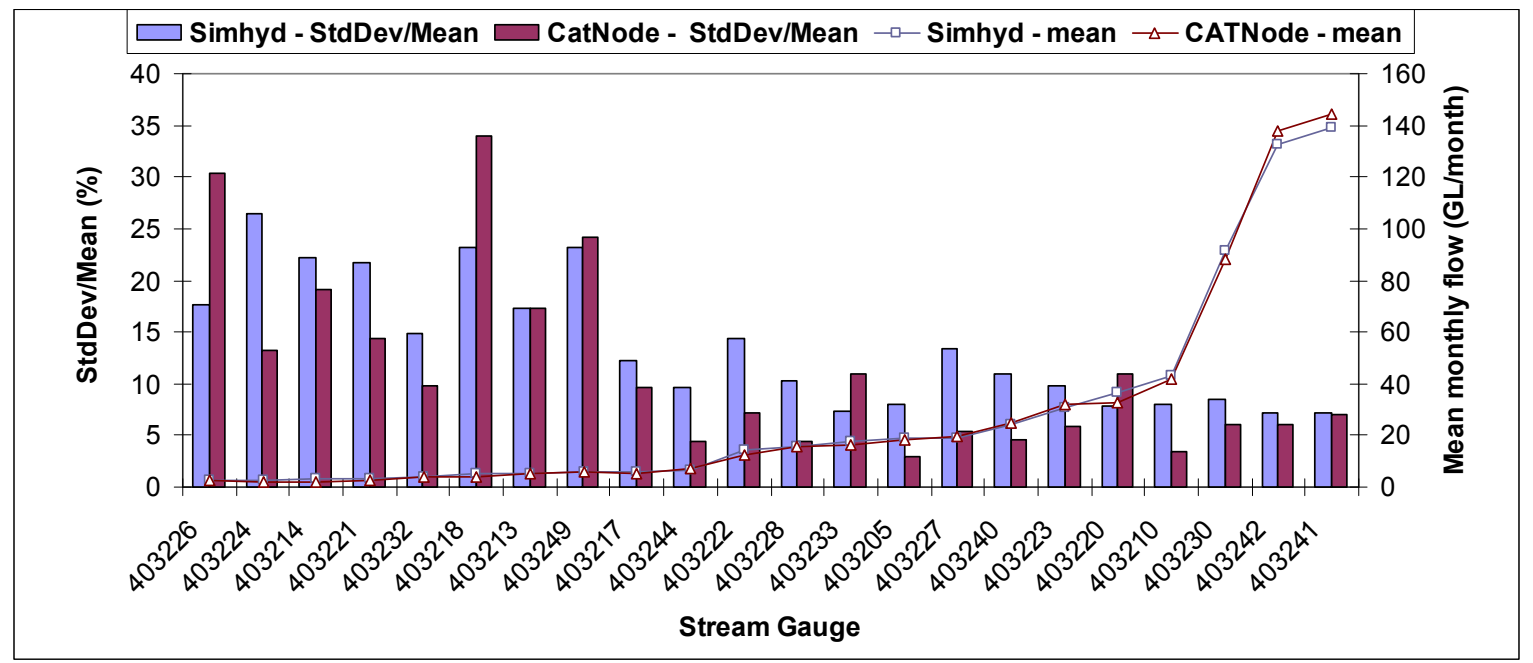

Figure 3. Mean of the standard deviation of the monthly flow over the three calibration regimes as a percentage of mean monthly flow (StdDev/Mean) and the mean monthly flow in GL/month predicted for all stream gauges using the Simhyd and CATNode models. Calculated over the period 1975-2010.

\subsection{Variability in the relative change in streamflow between different climate regimes}

In terms of assessing the impacts of climate change on streamflow the ultimate aim was to not ensure perfect calibration and validation against streamflow but ensure that the relative change in streamflow between different climate regimes was fairly consistent between different calibrations. As an example the percent decrease in mean monthly streamflow from the wet to average regime has been presented in Figure 4 . For this example the standard deviation in the percent decrease in streamflow ranged between 1 to $12 \%$ over the 22 sub-catchments. CATNode averaged 3.4\% and Simhyd 5.9\% with a difference that was statistically significant $(\mathrm{p}=0.01)$.

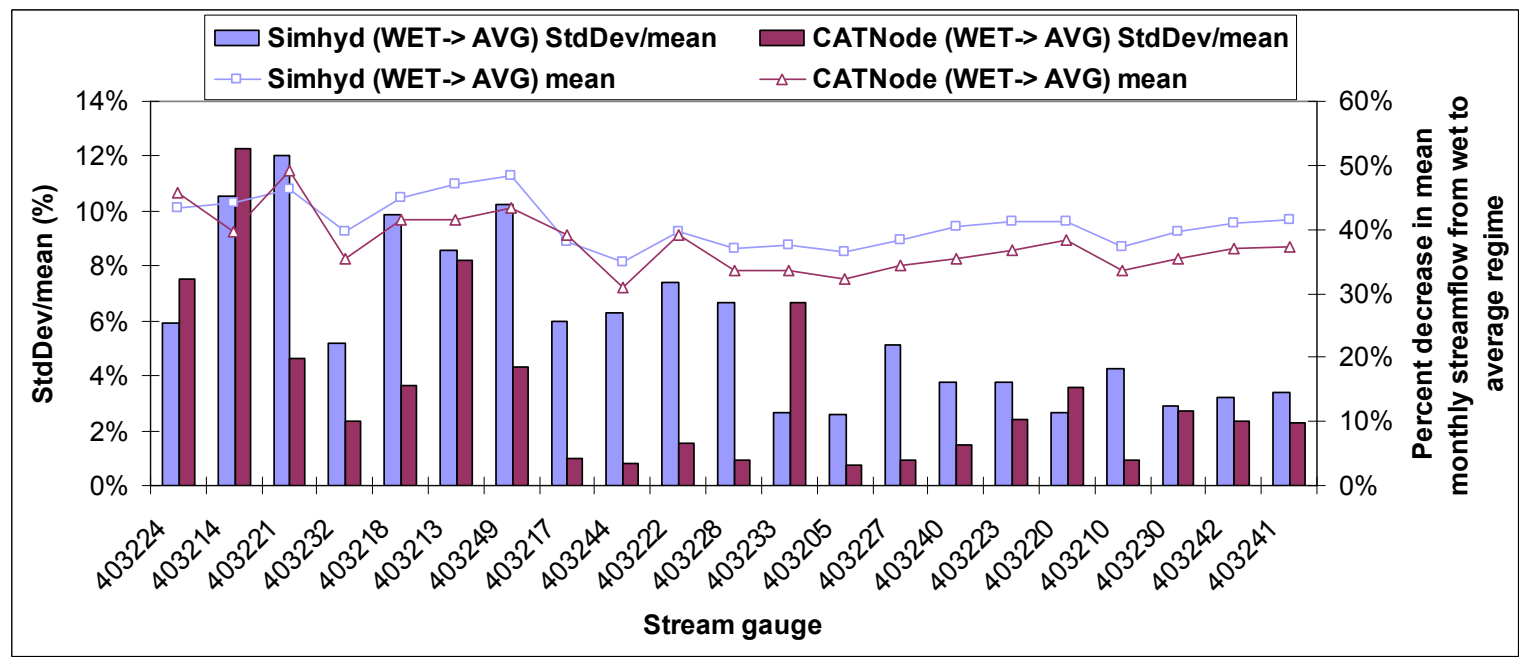

Figure 4. The percentage decrease in mean monthly streamflow from the wet to the average regime, averaged over the three calibrations with the standard deviation as a percentage of this mean

The percent decrease in mean monthly streamflow between each climate regime averaged over the 22 subcatchments has been presented in Table 4. Notably the uncertainty associated with the percent decrease in streamflow was considerably lower than the uncertainty in model predictions due to different calibrations. Results consistently showed that the uncertainty in the percent-decrease-in-streamflow was significantly lower for CATNode than Simhyd. This would be expected given the fixed monthly evapotranspiration of CATNode compared to the dynamic parameterisation of evapotranspiration in Simhyd. Both the CATNode and Simhyd models predicted similar average percent decrease in streamflow when moving from one climate regime to another. In each scenario the models predicted that the percent decrease in streamflow was nearly double the percent decrease in rainfall. 
Weeks et al., The ability of streamflow models to capture the impact of climate variability on streamflow...

Table 4. The percent decrease in rainfall and streamflow moving between two climate regimes. Values are averaged over 22 sub-catchments. The uncertainty (StdDev/mean) is the standard deviation in the percent decrease in streamflow over the three calibrations as a proportion of the average percent decrease in streamflow.

\begin{tabular}{|l|l|l|l|l|l|}
\hline & \multicolumn{2}{|c|}{ CATNode } & \multicolumn{2}{c|}{ Simhyd } \\
\hline $\begin{array}{l}\text { Change in } \\
\text { climate regime }\end{array}$ & $\begin{array}{l}\text { Average percent } \\
\text { decrease in } \\
\text { rainfall (\%) }\end{array}$ & $\begin{array}{l}\text { Average percent } \\
\text { decrease in } \\
\text { streamflow (\%) }\end{array}$ & $\begin{array}{l}\text { StdDev/mean } \\
(\%)\end{array}$ & $\begin{array}{l}\text { Average percent } \\
\text { decrease in } \\
\text { streamflow (\%) }\end{array}$ & $\begin{array}{l}\text { StdDev/mean } \\
(\%)\end{array}$ \\
\hline Wet $\rightarrow$ Avg & 19.3 & 37.8 & 3.4 & 40.8 & 5.9 \\
\hline Wet $\rightarrow$ Dry & 42.6 & 73.1 & 2.5 & 74.0 & 4.1 \\
\hline Avg $\rightarrow$ Dry & 28.8 & 57.3 & 4.1 & 56.3 & 6.6 \\
\hline
\end{tabular}

\section{CONCLUSIONS}

Two streamflow models, Simhyd and CATNode were assessed for their ability to predict streamflow when calibrated under different historical climate regimes. Statistical analysis based on the Nash Sutcliffe Coefficient of Efficiency $(\mathrm{CoE})$, gradient and percent difference in cumulative flow found that for each model over $90 \%$ of sub-catchments met the goodness-of-fit acceptability criteria. The models both validated well over the wet and average regimes, but validated poorly over the dry regime. Whilst the omission of factors such as extractions and dam releases may have contributed to this poor validation there was evidence that a model calibrated under wet conditions was biased towards those conditions. Consequently, if a future, drier scenario was used in these models, equivalent to moving from an average or wet regime to a dry regime, these models could potentially over-predict streamflow and under-estimate the impacts of climate change. On average the uncertainty in the monthly streamflow due to the different regimes of calibration was considerable, ranging between 8 to $35 \%$ of the mean monthly flow for the 22 sub-catchments. Although this uncertainty was large, in terms of assessing the impacts of climate change on streamflow it was perhaps more important to consider the uncertainty around the relative change in streamflow between different climate regimes. Results showed that the uncertainty associated with the percent decrease in streamflow ranged between 2.5 to $4.1 \%$ for CATNode and 4.1 to $6.6 \%$ for Simhyd. If, under future scenarios of climate change, the relative shift in streamflow was greater than this uncertainty we would now have greater confidence that this change was climate driven and not an artefact of the model calibration data.

\section{REFERENCES}

Barlow, K.M., Weeks, A. and F. Githui, 2011. Investigation of the use of PEST to optimise a Source catchments model of streamflow in the Ovens River Australia. Proceedings of the $34^{\text {th }}$ IAHR Word Congress. $26^{\text {th }}$ June to $1^{\text {st }}$ July, Brisbane.

Chiew, F.H.S., Teng, T., Vaze, J. and D.G.C. Kirono, 2009. Influence of global climate model selection on runoff impact assessment. Journal of Hydrology 379, Elsevier, pp. 172-180.

Chiew, F.H.S., Kirono, D.G.C., Kent, D.M., Frost, A.J., Charles, S.P., Timbal, B., Nguyen, K.C. and G. Fu, 2010. Comparison of runoff modelled using rainfall from different downscaling methods for historical and future climates. Journal of Hydrology 387, Elsevier, pp. 10-23.

Jeffrey, S.J., Carter, J.O., Moodie, K.M and A.R. Beswick, 2001. Using spatial interpolation to construct a comprehensive archive of Australian climate data, Environmental Modelling and Software 16(4), pp. 309330 .

Nash, J.E. and J.V. Sutcliffe (1970). River flow forecasting through conceptual models part I - A discussion of principles. Journal of Hydrology 10(3), pp. 282-290.

Murray darling Basin Authority, 2011. Guide to the proposed Basin Plan Volume 1. 3.7 The context for decisions - approach to including climate change. ISBN (online) 978-1-921557-73-6. pp. 34

Stenson, M.P., Littleboy, M. and M. Gilfedder, 2011. Estimation of water and salt generation from unregulated upland catchments. Environmental Modelling and Software 26, pp. 1268-1278.

Weeks, A., Christy, B., Lowell K. and C. Beverly (2008). The Catchment Analysis Tool: demonstrating the benefits of interconnected biophysical models. In Landscape Analysis and Visualisation. C. Pettit, W. Cartwright, I. Bishop et al.(eds). Berlin, Springer-Verlag: 49-71. 